Check for updates

Cite this: RSC Adv., 2017, 7, 42146

Received 21st July 2017

Accepted 25th August 2017

DOI: $10.1039 / c 7 r a 08047 f$

rsc.li/rsc-advances

\section{Nickel tungstate-graphene nanocomposite for simultaneous electrochemical detection of heavy metal ions with application to complex aqueous media $\uparrow$}

\begin{abstract}
Rudra Kumar, (D $t^{\mathrm{a}}$ Thiruvelu Bhuvana (D) $t^{* \mathrm{~b}}$ and Ashutosh Sharma*a
We show for the first time that a composite of carbon and binary transition metal oxide, in the form of a reduced graphene oxide and nickel tungstate $\left(\mathrm{RGO} / \mathrm{NiWO}_{4}\right)$ nanocomposite, is an effective material for electrochemical heavy metal ions detection. The multivalent electronic states of this composite show well-defined peaks of $\mathrm{Cd}(॥), \mathrm{Pb}(॥), \mathrm{Cu}(॥)$ and $\mathrm{Hg}(॥)$ during simultaneous detection, which is otherwise not observed for $\mathrm{NiWO}_{4} \mathrm{NPS}$ and RGO sheets. Simultaneous and selective detection of heavy metal ions in drinking water as well as in complex aqueous media such as carbonated drinks, milk and fruit juices has been successfully demonstrated. Differential pulse anodic stripping voltammetric (DPASV) method was adopted for detection because it partially suppresses the background current and improves signal which leads to a low limit of detection (LOD) when compared to linear sweep voltammetry (LSV). LOD for $\mathrm{Cd}(॥), \mathrm{Pb}(॥), \mathrm{Cu}(॥)$ and $\mathrm{Hg}(॥)$ ions were found to be $4.7 \times 10^{-10} \mathrm{M}, 3.8 \times 10^{-10} \mathrm{M}, 4.4 \times 10^{-10} \mathrm{M}$ and $2.8 \times 10^{-10} \mathrm{M}$ for individual detection and $1.0 \times 10^{-10}, 1.8 \times 10^{-10}, 2.3 \times 10^{-10}$ and $2.8 \times 10^{-10} \mathrm{M}$, for simultaneous detection, respectively. The effect of deposition time and deposition potential on the sensing parameter was studied in acetate buffer $(\mathrm{pH}=5.0)$. The better sensitivity with the high capacitive current along with individual and simultaneous electrochemical detection of $\mathrm{RGO} / \mathrm{NiWO}_{4}$ nanocomposite is mainly attributed to its large surface area, good electronic conductivity, and better electron transport properties which lead to better catalytic response towards the heavy metal ions detection.
\end{abstract}

\section{Introduction}

Trace amounts of heavy metal may cause serious health issues in living organisms because of their tendency to accumulate in the major organs in humans and animals. ${ }^{1,2}$ Heavy metal ions such as $\mathrm{Cu}$ (II), $\mathrm{Cd}$ (II), $\mathrm{Pb}$ (II) and $\mathrm{Hg}$ (II) are a major threat as once absorbed, even in trace amounts, can cause serious adverse effects on the immune, central nervous and reproductive systems. ${ }^{3,4}$ Hence, it is important to develop simple, fast, accurate and cost-effective methods to simultaneously detect these toxic metal ions present in trace amounts. In order to detect these heavy metal ions several spectrometric methods such as atomic absorption spectroscopy (AAS), inductively coupled plasma mass spectrometry (ICP-MS), UV-Vis spectroscopy X-ray fluorescence spectroscopy (XFS) and inductively

${ }^{a}$ Department of Chemical Engineering, Indian Institute of Technology, Kanpur 208016, India. E-mail: ashutos@iitk.ac.in

${ }^{b}$ Department of Mechanical Engineering, Indian Institute of Technology, Kanpur 208016, India. E-mail: bhuvana@iitk.ac.in

$\dagger$ Electronic supplementary information (ESI) available. See DOI: $10.1039 / \mathrm{c} 7 \mathrm{ra08047f}$

$\ddagger$ contributed equally. coupled plasma atomic emission spectrometry (ICP-AES) are employed routinely..$^{1-3}$ However, these methods require excessive amounts of time, expensive instrumentation and high operating cost. Quite the reverse, the electrochemical method ${ }^{5-7}$ offers an exciting alternative due to its numerous advantages. It is simple, rapid, portable and cost effective in order to detect heavy metals at greater accuracy and high sensitivity and above all, it is user-friendly. Electrochemistry itself offers a host of techniques depending on detection range, such as for higher concentrations $\left(>10^{-5} \mathrm{M}\right)$ linear sweep voltammetry (LSV) is employed, however, for lower concentrations, the double-layer charging current is not negligible as the faradic current becomes smaller and thus pulse techniques, i.e., normal pulse (NPV), square wave (SWV) and differential pulse (DPV) voltammetry are employed wherein partial suppression the background current occurs and thus improving LOD. One of the pulsed techniques, differential pulse anodic stripping voltammetry (DPASV) involves the sensing mechanism by accumulating the target metal ions on the surface of the electrode during the applied potential and the electron transportation between the electrode material and metal ions. This method also offers detection of a very low concentration of metal ions 
and simultaneous detection of various types of heavy metal ions with high sensitivity, thus this method is ideal.

Pure NiO has a cubic structure and is classified as a MottHubbard insulator with room temperature conductivity less than $10^{-13} \mathrm{~S} \mathrm{~cm}^{-1}$, which will greatly reduce its electrochemical properties..$^{8-10}$ The incorporation of $\mathrm{W}$ atoms can greatly enhance the conductivity of $\mathrm{NiWO}_{4}$ in comparison with pure $\mathrm{NiO}$. Therefore, nickel tungstate $\left(\mathrm{NiWO}_{4}\right)$ possesses high electrical conductivity $\left(10^{-7}\right.$ to $\left.10^{-2} \mathrm{~S} \mathrm{~cm}^{-1}\right)$ than many single transition metal oxides and multivalent binary oxides e.g. $\mathrm{NiMoO}_{4}$ (ref. 11) $\sim 10^{-11}$ to $10^{-4.5} \mathrm{~S} \mathrm{~cm}^{-1} \mathrm{FeWO}_{4}$ (ref. 12) $\sim 10^{-6} \mathrm{~S} \mathrm{~cm}^{-1}$ and $\mathrm{Bi}_{2} \mathrm{WO}_{6} \sim 10^{-8} \mathrm{~S} \mathrm{~cm}^{-1}{ }^{13}$ This material has low synthesis cost, low corrosion, high stability and high electrocatalytic activity. Further, it is environmentally friendly and has been utilised in a wide variety of applications such as supercapacitors, lithium-ion battery, and electrocatalyst. ${ }^{14}$ However, the agglomeration of individual nanoparticles leading to low surface area severely hinders the electro-catalytic performance. Additionally, the electrical conductivity of transition metal oxides is far less than the carbonaceous material, which further reduces the electro-catalytic performance. Therefore, to facilitate the better electrochemical, electrocatalytic performance and improving electrical conductivity, incorporation of carbonaceous materials is essential. Among all types of carbon sources, graphene is an appropriate 2-D material owing to its high surface area, good electrical conductivity, superior flexibility, electronic transport properties and excellent electro-catalytic activity. However, the agglomeration of individual graphene sheets due to restacking and consequent surface area reduction limited its applicability. Here, among other things, the problem of restacking of individual graphene sheets is overcome by incorporation of metal oxide nanoparticles.

Although there is a vast literature on electrochemical sensing of heavy metal ions, there are only a few reports on the simultaneous and selective electrochemical sensing of toxic metal ions. Recently, Wei et al. ${ }^{15}$ demonstrated the electrochemical detection of heavy metal ions using $\mathrm{SnO}_{2} / \mathrm{RGO}$ nanocomposite. Xie et al. ${ }^{16}$ utilised $\mathrm{CeO}_{2} / \mathrm{RGO}$ nanocomposite for the simultaneous detection of heavy metal ions. Further, Xiong et al. ${ }^{17}$ demonstrated the use of $\mathrm{RGO}-\mathrm{Fe}_{3} \mathrm{O}_{4}$ nanocomposite and Lee et al. ${ }^{18}$ employed RGO decorated with tin nanoparticles for heavy metal detection in soil and tap water respectively. Apart from metal oxide and graphene composites, numerous types of modified electrodes were tested for the detection of toxic metals such as carbon nanotubes, ${ }^{19}$ gold nanoparticles,${ }^{20}$ mesoporous silica, ${ }^{21}$ polypyrrole/carbonaceous nanospheres, ${ }^{22}$ tin oxide nanoparticles ${ }^{23}$ thiacalixarene-functionalized graphene oxide ${ }^{24}$ and palladium nanoparticle incorporated porous activated carbon. ${ }^{25}$

Here, we present a simple hydrothermal synthesis of reduced graphene oxide and nickel tungstate $\left(\mathrm{RGO} / \mathrm{NiWO}_{4}\right)$ nanocomposite to investigate the simultaneous and effective detection of $\mathrm{Cu}$ (II), $\mathrm{Cd}$ (II), $\mathrm{Pb}$ (II) and $\mathrm{Hg}$ (II) metal ions by DPASV. The $\mathrm{RGO} / \mathrm{NiWO}_{4}$ nanocomposite exhibited enhanced sensing performance as compared to pristine $\mathrm{RGO}$ and $\mathrm{NiWO}_{4} \mathrm{NPs}$. The binary metal oxide nanoparticles not only act as spacers to reduce the restacking of individual graphene sheets but also behave as an electrochemical catalyst, which enhances the sensing performance. Our results suggest that the $\mathrm{RGO} / \mathrm{NiWO}_{4}$ nanocomposite can indeed be used as an effective electrocatalyst for the simultaneous detection of toxic heavy metal ions. Not limited to testing in water, these fabricated electrodes exhibited excellent sensing properties even in complex aqueous media of carbonated drinks, milk and fruit juices, thus offering a great potential for wider application as a metal ion sensor.

\section{Experimental section}

\section{Materials}

Sodium tungstate dihydrate $\left(\mathrm{Na}_{2} \mathrm{WO}_{4} \cdot 2 \mathrm{H}_{2} \mathrm{O}\right)$, and nickel chloride $\left(\mathrm{NiCl}_{2} \cdot 6 \mathrm{H}_{2} \mathrm{O}\right)$ were purchased from Fisher Scientific. Acetic acid glacial, cadmium nitrate $\left(\mathrm{Cd}\left(\mathrm{NO}_{3}\right)_{2}\right)$, copper nitrate $\left(\mathrm{Cu}\left(\mathrm{NO}_{3}\right)_{2}\right)$, mercury nitrate $\left(\mathrm{Hg}\left(\mathrm{NO}_{3}\right)_{2} \cdot \mathrm{H}_{2} \mathrm{O}\right)$, lead nitrate $\left(\mathrm{Pb}\left(\mathrm{NO}_{3}\right)\right)$, graphite flakes, sulphuric acid $\left(\mathrm{H}_{2} \mathrm{SO}_{4}\right)$, sodium nitrate $\left(\mathrm{NaNO}_{3}\right)$, sodium acetate $\left(\mathrm{CH}_{3} \mathrm{COONa}\right)$ and potassium permanganate $\left(\mathrm{KMnO}_{4}\right)$ were purchased from Loba Chemie. DI water was used for solution preparation.

\section{Methods}

Synthesis of $\mathrm{RGO} / \mathrm{NiWO}_{4}$ nanocomposite. Modified Hummer's method was used to synthesise graphene oxide (GO) as reported previously. ${ }^{26}$ Reduced graphene oxide/nickel tungstate $\left(\mathrm{RGO} / \mathrm{NiWO}_{4}\right)$ nanocomposite were synthesised via hydrothermal method by mixing GO with nickel and tungsten salts followed by calcination and pyrolysis in air and nitrogen atmosphere, respectively. ${ }^{14}$ Briefly, $2 \mathrm{mg} \mathrm{ml}^{-1}$ aqueous suspension of GO was stirred with $2 \mathrm{mmol} \mathrm{NiCl}_{2} \cdot 6 \mathrm{H}_{2} \mathrm{O}$ for $1 \mathrm{~h}$ at room temperature. After complete mixing, $2 \mathrm{mmol}$ of $\mathrm{Na}_{2} \mathrm{WO}_{4} \cdot 2 \mathrm{H}_{2} \mathrm{O}$ was added and stirred for another $1 \mathrm{~h}$. The resulting solution was transferred into $50 \mathrm{ml}$ hydrothermal reactor and heated at $180^{\circ} \mathrm{C}$ for $12 \mathrm{~h}$. After completion of the reaction, the reactor was cooled to room temperature and the product was collected by centrifugation. The collected product was washed several times with ethanol and water followed by drying at $80^{\circ} \mathrm{C}$ overnight. Finally, the dried product was heated in air at $400^{\circ} \mathrm{C}$ for $2 \mathrm{~h}$ followed by pyrolysis in a nitrogen atmosphere for $2 \mathrm{~h}$ at $600^{\circ} \mathrm{C}$. Neat $\mathrm{NiWO}_{4}$ NPs were also prepared by adopting the same procedure but without the addition of GO.

Characterisation $\mathbf{R G O} / \mathrm{NiWO}_{4}$ nanocomposite. The morphological structure of $\mathrm{RGO} / \mathrm{NiWO}_{4}$ nanocomposite was visualised by field emission scanning electron microscopy (FESEM, ZEISS Supra 40VP, Germany) and transmission electron microscopy (TEM, FEI Tecnai $\mathrm{G}^{2} 12$ Twin, USA). Energy dispersive X-ray spectroscopy (EDX, Oxford Instruments, England) combined with elemental mapping was performed in FESEM to determine the elemental composition. X-ray diffraction (XRD, PAN analytical, Germany) of the nanocomposite was measured from $5^{\circ}$ to $80^{\circ}$ with $\mathrm{Cu} \mathrm{K} \alpha$ radiation. Thermogravimetric analysis (TGA, TA instrument, USA) was performed in air with a heating rate of $10{ }^{\circ} \mathrm{C} \mathrm{min}{ }^{-1}$.

Electrochemical measurements. The electrodes were prepared by mixing the nanocomposite, acetylene black, and 
poly(vinylidenefluoride) (PVDF) with the mass ratio of $80: 10: 10$ and dispersed in $N$-methylpyrrolidone (NMP). The mixture was stirred till it formed a homogeneous slurry, then the slurry was dip-coated onto carbon paper and dried under vacuum at $120{ }^{\circ} \mathrm{C}$ for $24 \mathrm{~h}$. The loading mass of each working electrode was about 2-3 mg, and each working electrode had a geometric surface area of about $1 \mathrm{~cm}^{2}$. In a three-electrode system, $0.1 \mathrm{M}$ acetate buffer ( $\mathrm{pH}$ 5.0) was used as the electrolyte, platinum rod and $\mathrm{Ag} / \mathrm{AgCl}(3 \mathrm{M} \mathrm{KCl}-$ saturated) electrode was used as the counter and a reference electrode, respectively. Cyclic voltammetry (CV), electrochemical impedance spectroscopy (EIS) measurements and differential pulse anodic stripping voltammetry (DPASV) were performed using an electrochemical workstation (Autolab PGSTAT 302N). EIS was recorded under the following conditions: $\mathrm{AC}$ voltage amplitude of $10 \mathrm{mV}$, the frequency range of $1 \times 10^{5}$ to $0.1 \mathrm{~Hz}$, and open circuit potential.

Individual detection of $\mathrm{Cd}(\mathrm{II}), \mathrm{Pb}$ (II), $\mathrm{Cu}$ (II), and $\mathrm{Hg}$ (II) ions. In order to detect heavy metal ions, differential pulse anodic stripping voltammetry (DPASV) was employed. The deposition potential of $\mathrm{Cu}$ (II), $\mathrm{Cd}$ (II), $\mathrm{Pb}$ (II), and $\mathrm{Hg}$ (II) was performed at $-1.0 \mathrm{~V}$ for $120 \mathrm{~s}$ in $0.1 \mathrm{M}$ acetate buffer ( $\mathrm{pH} 5.0$ ) by the reduction to their respective metallic state. The re-oxidation of metal to metal ions, i.e., anodic stripping of electrodeposited metal was performed at various potentials ranging from 0.5 to $1 \mathrm{~V}$ with $25 \mathrm{mV}$ amplitude, $15 \mathrm{~Hz}$ frequency, and $4 \mathrm{mV}$ increment potential and similar experimental conditions were used to perform the selective/individual and simultaneous detection of $\mathrm{Cu}(\mathrm{II}), \mathrm{Cd}(\mathrm{II}), \mathrm{Pb}(\mathrm{II})$, and $\mathrm{Hg}$ (II) ions.

\section{Results and discussion}

Scheme 1 shows the schematic of synthesis process of RGO/ $\mathrm{NiWO}_{4}$ nanocomposite. As stated before, negatively charged GO was dispersed in distilled water followed by addition of nickel and tungsten salts. During the addition of nickel salt, positively charged $\mathrm{Ni}^{2+}$ cations were adsorbed on negatively charged GO by electrostatic interaction. After, completion of the process, the solution became positively charged which assisted in adsorption of $\mathrm{WO}_{4}{ }^{2-}$ anions during the addition of tungstate salt. The functional groups present on the surface of graphene oxide were reduced by hydrothermal treatment. The crystallisation of $\mathrm{NiWO}_{4}$ occurred by high-temperature pyrolysis initially at $400{ }^{\circ} \mathrm{C}$ in air and then at $600{ }^{\circ} \mathrm{C}$ in nitrogen atmosphere.
Following are the governing reactions for the formation of $\mathrm{NiWO}_{4}$.

After dissolution of salt at room temperature:

$$
\begin{gathered}
\mathrm{Na}_{2} \mathrm{WO}_{4} \cdot 2 \mathrm{H}_{2} \mathrm{O}+2 \mathrm{H}_{2} \mathrm{O} \rightarrow 2 \mathrm{Na}^{+}+2 \mathrm{H}_{2} \mathrm{O} \\
\mathrm{NiCl}_{2} \cdot 6 \mathrm{H}_{2} \mathrm{O} \rightarrow \mathrm{Ni}^{2+}+2 \mathrm{Cl}^{-}+6 \mathrm{H}_{2} \mathrm{O}
\end{gathered}
$$

After hydrothermal treatment:

$$
\begin{aligned}
2 \mathrm{Na}^{+}+\mathrm{WO}_{4}{ }^{2-}+2 \mathrm{H}_{2} \mathrm{O}+\mathrm{Ni}^{2+}+2 \mathrm{Cl}^{-}+6 \mathrm{H}_{2} \mathrm{O} \rightarrow \\
\mathrm{NiWO}_{4}+2 \mathrm{Na}^{+}+2 \mathrm{Cl}^{-}+8 \mathrm{H}_{2} \mathrm{O}
\end{aligned}
$$

\section{Morphology of RGO/NiWO 4 nanocomposite}

Initially, the composition of the nanocomposite was confirmed using XRD and thermogravimetric analysis and results are discussed in Fig. 1. X-ray diffraction pattern was recorded for GO, RGO, $\mathrm{NiWO}_{4}$ and $\mathrm{RGO} / \mathrm{NiWO}_{4}$ nanocomposite and their respective diffraction patterns are shown in Fig. 1a. For GO, the diffraction peak observed at $2 \theta$ of $10.5^{\circ}$ reflected (002) plane of exfoliated GO sheets with interlayer $d$-spacing of $0.8 \mathrm{~nm} .{ }^{26} \mathrm{After}$ reduction of GO to RGO, the peak at $10.5^{\circ}$ of GO disappeared completely and a new peak appeared at $26^{\circ}$ indicating the formation of RGO. For $\mathrm{NiWO}_{4} \mathrm{NPs}$, diffraction peaks were observed at $19.2^{\circ}, 23.9^{\circ}, 24.9^{\circ}, 30.9^{\circ}, 36.5^{\circ}, 39.1^{\circ}, 41.6^{\circ}, 46.4^{\circ}$, $52.3^{\circ}, 54.6^{\circ}, 62.3^{\circ}, 65.8^{\circ}, 68.9^{\circ}, 72.3^{\circ}$ and $79.3^{\circ}$ which corresponded to (100), (011), (110), (-111), (002), (200), (-102), (-211), (130), (-202), (-113), (-311), (041), (-141) and (-223) planes of wolframite monoclinic structure with $P 2 / c$ space group of $\mathrm{NiWO}_{4}\left(\mathrm{JCPDS}\right.$ file no. 15-0755). ${ }^{27}$ The crystallite size of $\mathrm{NiWO}_{4} \mathrm{NPs}$ was measured as $21 \mathrm{~nm}$ at $2 \theta$ of $30.9^{\circ}$ using Scherrer equation. In the case of $\mathrm{RGO} / \mathrm{NiWO}_{4}$ nanocomposite, diffraction peaks due to graphene sheets were not seem due to the complete coverage of graphene by $\mathrm{NiWO}_{4} \mathrm{NPs}$ and that resulted in the strong shielding of the characteristic peak of graphene. Therefore, for $\mathrm{RGO} / \mathrm{NiWO}_{4}$ nanocomposite, the diffraction peaks completely matched with the peaks observed for $\mathrm{NiWO}_{4}$.

In order to determine the amount of loading of $\mathrm{NiWO}_{4}$ in $\mathrm{RGO} / \mathrm{NiWO}_{4}$ nanocomposite, TGA was performed in the air till $800^{\circ} \mathrm{C}$. TGA curve of $\mathrm{GO}, \mathrm{RGO}$, and $\mathrm{RGO} / \mathrm{NiWO}_{4}$ nanocomposite are shown in Fig. 1b. For GO, initial weight loss of $17 \%$ was observed below $100{ }^{\circ} \mathrm{C}$ due to the removal of surface adsorbed
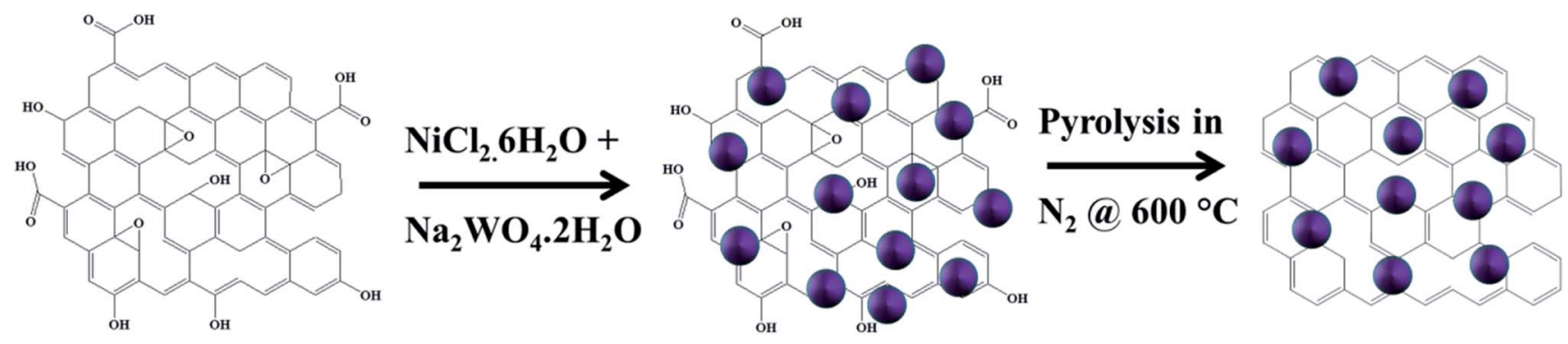

Scheme 1 Schematic representation of synthesis process of $\mathrm{RGO} / \mathrm{NiWO}_{4}$ nanocomposite. 

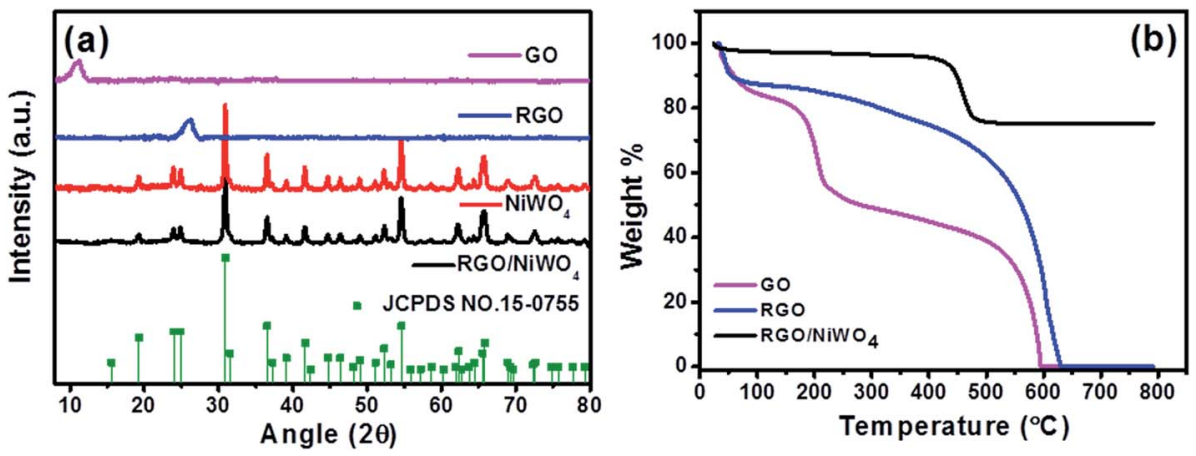

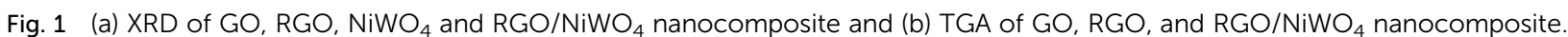

water. Around $200{ }^{\circ} \mathrm{C}$ functional groups degradation and complete decomposition around $600^{\circ} \mathrm{C}$ was observed. For RGO, initial weight loss of $12 \%$ was observed below $100^{\circ} \mathrm{C}$, due to the removal of surface adsorbed water. The complete burning of carbon occurred at $600{ }^{\circ} \mathrm{C}$ confirming no impurity present in the sample. $\mathrm{RGO} / \mathrm{NiWO}_{4}$ nanocomposite showed $26 \%$ weight loss at $450-600{ }^{\circ} \mathrm{C}$ mainly due to the burning of graphene in the air. Beyond $600{ }^{\circ} \mathrm{C}$, there was no weight loss observed due to complete removal of carbon species. TGA result confirmed that $\sim 74 \quad$ wt $\% \quad \mathrm{NiWO}_{4} \quad \mathrm{NPs}$ was loaded in $\mathrm{RGO} / \mathrm{NiWO}_{4}$ nanocomposite.

The morphology of $\mathrm{GO}, \mathrm{NiWO}_{4} \mathrm{NPs}$, and $\mathrm{RGO} / \mathrm{NiWO}_{4}$ nanocomposite was confirmed using electron microscopy. TEM and SEM were performed in order to visualise the samples and their respective images are shown in Fig. 2. TEM and SEM image of GO sheets, shown in Fig. 2a and d respectively, displayed transparent but wrinkled sheet morphology. The lateral dimension of GO sheets is in microns and the sheet thickness is in nanometres. $\mathrm{NiWO}_{4} \mathrm{NPs}$ with size ranging from 20 to $50 \mathrm{~nm}$ can be seen in Fig. $2 \mathrm{~b}$ and e. The inset in Fig. $2 \mathrm{~b}$ shows the SAED pattern with random and continuous bright spots confirming the polycrystalline nature of $\mathrm{NiWO}_{4} \mathrm{NPs}$. Further, the lattice fringes obtained from HRTEM indicated the inter-planner distance of $0.36 \mathrm{~nm}$ corresponding to (011) planes of $\mathrm{NiWO}_{4}$. Homogenous distribution of $\mathrm{NiWO}_{4} \mathrm{NPs}$ on RGO sheets in the nanocomposite of $\mathrm{NiWO}_{4}$ with RGO is clearly visualised from TEM and SEM images shown in Fig. $2 \mathrm{c}$ and $\mathrm{f}$ images. The inset of Fig. 2c showed the lattice fringes and SAED pattern of RGO/ $\mathrm{NiWO}_{4}$ nanocomposite, which further confirmed the polycrystalline nature. Fig. S2 (see ESI $\dagger$ ) showed the energy dispersive X-ray spectroscopy (EDX) confirming the composition and elemental mapping of $\mathrm{RGO} / \mathrm{NiWO}_{4}$ nanocomposite, which confirmed the homogeneous distribution of $\mathrm{C}, \mathrm{O}, \mathrm{Ni}$, and $\mathrm{W}$ elements. From these results, it is clear that RGO sheets
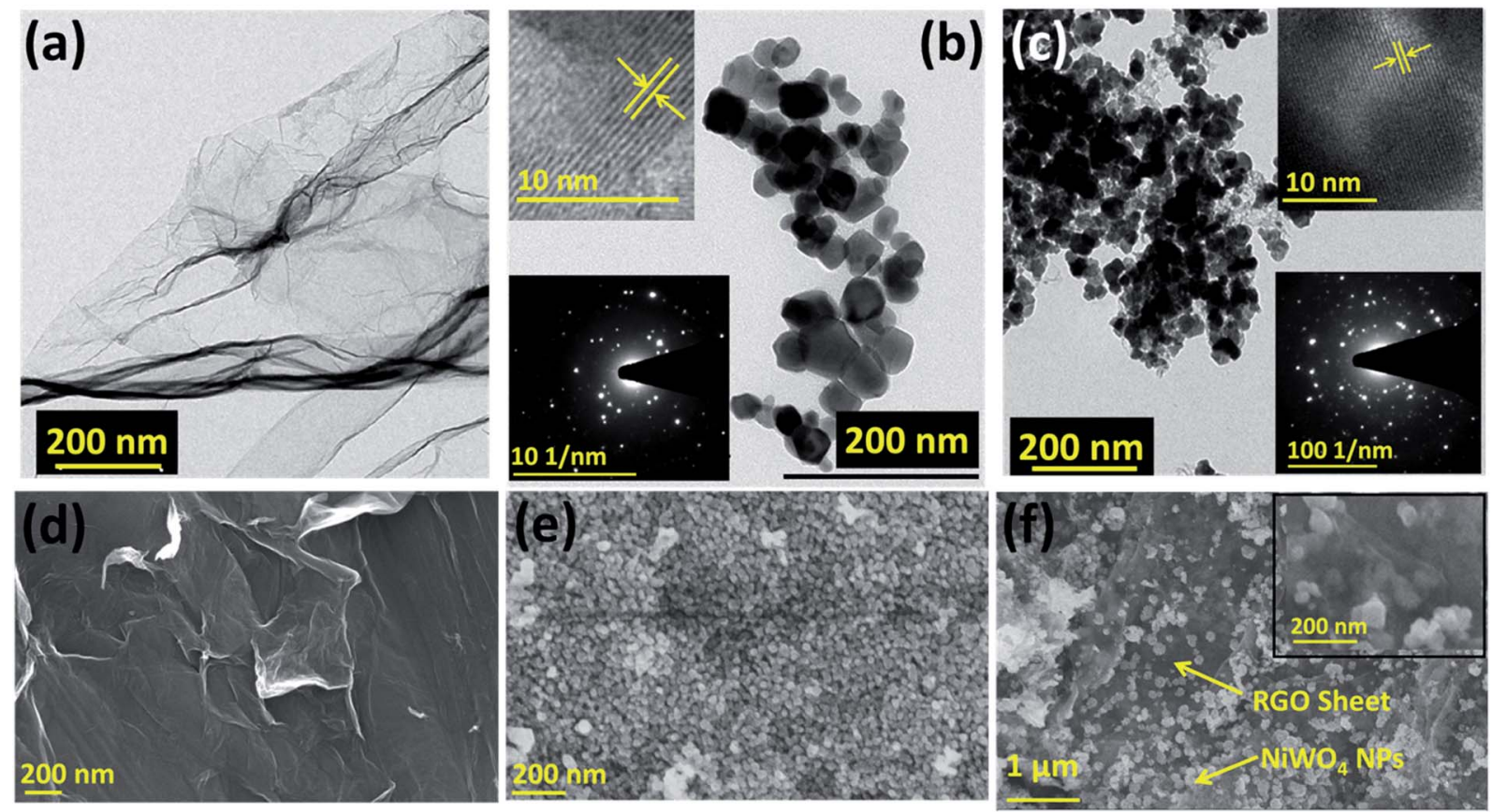

Fig. 2 TEM images of $(a-c)$ GO, NiWO 4 NPs and RGO/NiWO 4 nanocomposite with inset showing SAED and lattice fringes. SEM images of (d-f) $\mathrm{GO}, \mathrm{NiWO}_{4} \mathrm{NPs}$ and $\mathrm{RGO} / \mathrm{NiWO}_{4}$ nanocomposite. 
provided as 3-dimensional conductive support and a basal plane for the appropriate attachment of $\mathrm{NiWO}_{4} \mathrm{NPs}$ on the surface of RGO sheets.

\section{Electrochemical characterization of $\mathrm{RGO} / \mathrm{NiWO}_{4}$ nanocomposite}

Cyclic voltammetry and DPASV. Before performing electrochemical detection of toxic metal ions using the prepared electrodes, cyclic voltammetry was performed on bare CP, RGO, $\mathrm{NiWO}_{4}$ NPs and RGO/NiWO${ }_{4}$ nanocomposite coated on CP in aqueous solution of $0.1 \mathrm{M} \mathrm{KCl}$ containing $5 \mathrm{mM} \mathrm{Fe}(\mathrm{CN})_{6}{ }^{3-}$ in the voltage range of $-0.2 \mathrm{~V}$ to $0.6 \mathrm{~V}$ at a scan rate of $50 \mathrm{mV} \mathrm{s}^{-1}$. The CV recorded are shown in Fig. 3a, the anodic and cathodic peak current drawn by the CV curve for bare CP is the least among all the electrodes and RGO seem to be slightly better than CP. For the $\mathrm{NiWO}_{4} \mathrm{NPs}$, the current response in the $\mathrm{CV}$ is equivalent to that of RGO but with no obvious redox peaks which is mainly attributed to the agglomeration of individual nanoparticles and poor electronic conductivity, thus causing the hindrance of electron transfer on the electrode surface. $\mathrm{RGO} / \mathrm{NiWO}_{4}$ nanocomposite exhibited the highest current response among all the electrodes. This is mainly attributed to the larger surface area of the nanocomposite as the $\mathrm{NiWO}_{4} \mathrm{NPS}$ acted as spacers and prevented the restacking of the RGO sheets and also an agglomeration of individual NPs, hence causing the better conducting pathway for the electron transport and enhanced electro-catalytic process at the surface of nanocomposite electrode. Long cyclic stability of the electrode was studied by performing cyclic voltammetry. The electrode has been subjected to consecutive cycling in the potential range of -0.2 to $0.6 \mathrm{~V}$ for 200 cycles in $0.1 \mathrm{M} \mathrm{KCl}$ solution containing $5 \mathrm{mM} \mathrm{Fe}(\mathrm{CN})_{6}{ }^{3-}$. As shown in Fig. $3 \mathrm{~b}$, the peak current slightly increased up to 100 cycles and thereafter, no obvious changes were observed indicating good stability and reproducibility of the electrochemical performance of the electrode.

An electrochemical impedance spectroscopy (EIS) was employed to characterize the interfacial properties of the electrodes. Fig. 3c showed the Nyquist plot of the electrodes measured at the open-circuit potential in the frequency range from 0.01 to $10^{5} \mathrm{~Hz}$, where $\mathrm{Z}^{\prime}$ and $\mathrm{Z}^{\prime \prime}$ are the real and imaginary parts of the impedance, respectively. The semicircle at higher frequency range corresponded to the electron-transfer resistance $\left(R_{\mathrm{et}}\right)$, while a linear part at lower frequency range represented the diffusion limited process or Warburg resistance. The $R_{\text {et }}$ value of bare CP is highest among all the electrodes, which signified the poor electron transport. After coating the CP with RGO, $\mathrm{NiWO}_{4} \mathrm{NPs}$ and $\mathrm{RGO} / \mathrm{NiWO}_{4}$ nanocomposite, the semi circle domain with $R_{\text {et }}$ value decreased and the lowest value was observed for $\mathrm{RGO} / \mathrm{NiWO}_{4}$ nanocomposite, suggesting better electron transfer process at nanocomposite electrode surface. The inset in Fig. 3c displayed the enlarged view of the Nyquist plot of $\mathrm{RGO} / \mathrm{NiWO}_{4}$ nanocomposite for better visualization.

Further, DPASV was performed on bare CP, RGO, $\mathrm{NiWO}_{4} \mathrm{NPS}$ and $\mathrm{RGO} / \mathrm{NiWO}_{4}$ nanocomposite. The deposition process was
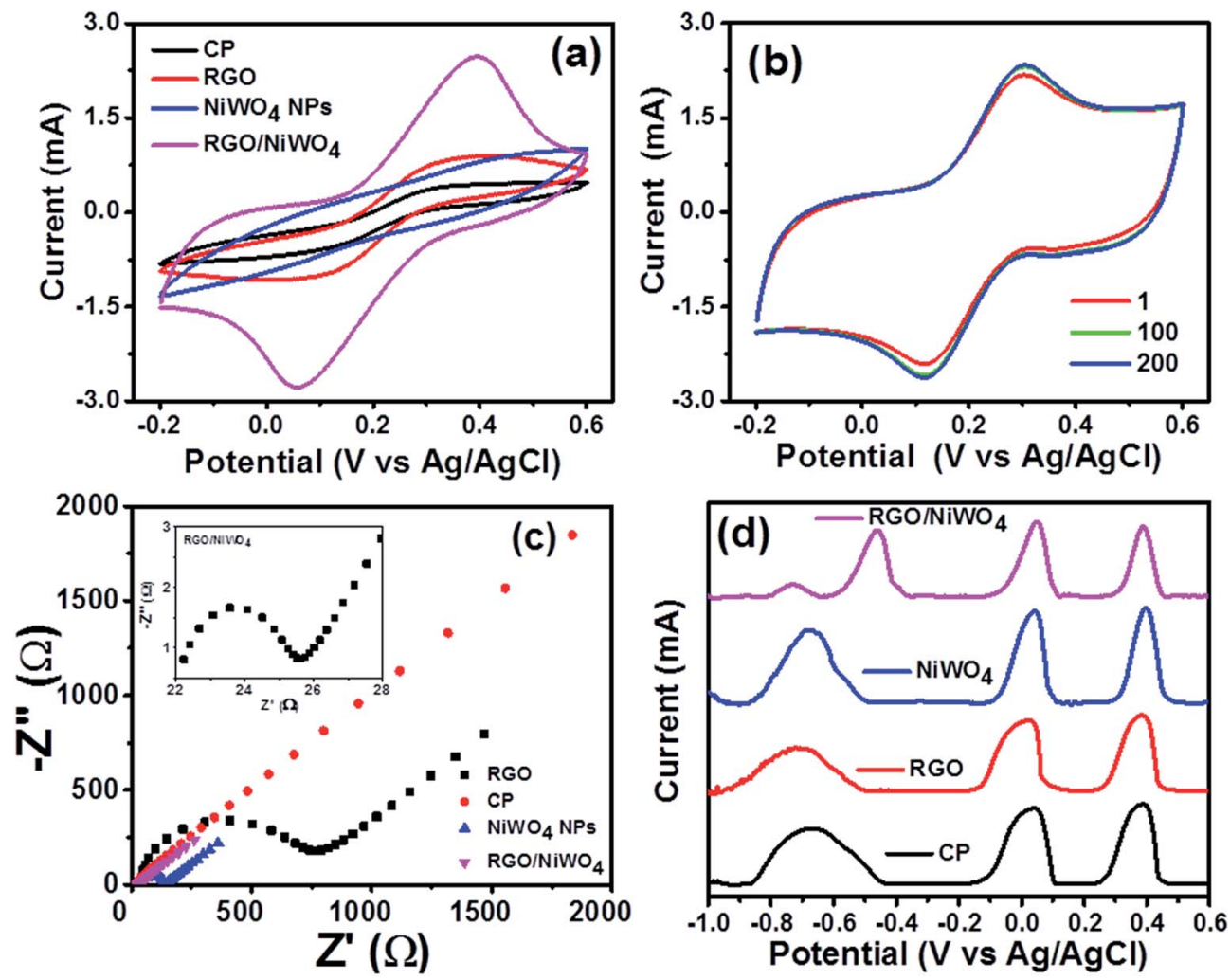

Fig. 3 (a) CV (b) CV with a different number of scanning cycles 1-200 with a scan rate of $50 \mathrm{mV} \mathrm{s}^{-1}$ (c) EIS with inset showing the zoomed-in image and (d) DPASV response of bare $\mathrm{CP}, \mathrm{RGO}, \mathrm{NiWO}_{4} \mathrm{NPs}$ and $\mathrm{RGO} / \mathrm{NiWO}_{4}$ nanocomposite. Electrolyte: $5 \mathrm{mM} \mathrm{Fe}(\mathrm{CN})_{6}{ }^{3-/ 4-}$ in $0.1 \mathrm{M} \mathrm{KCl}$. 
carried out in a solution containing $0.1 \mu \mathrm{M}$ each of $\mathrm{Cd}(\mathrm{II}), \mathrm{Pb}(\mathrm{II})$, $\mathrm{Cu}$ (II), and $\mathrm{Hg}$ (II) ions at $-1.0 \mathrm{~V}$ for 120 seconds in $0.1 \mathrm{M}$ acetate buffer ( $\mathrm{pH}$ 5.0) and the results were shown in Fig. 3d. Three peaks were observed for bare $\mathrm{CP}$, RGO and $\mathrm{NiWO}_{4} \mathrm{NPs}$ in the range of $-1.0 \mathrm{~V}$ to $0.6 \mathrm{~V}$, however, four sharp and distinct peaks were observed for $\mathrm{RGO} / \mathrm{NiWO}_{4}$ nanocomposite. Individually, peaks due to $\mathrm{Cd}(\mathrm{II}), \mathrm{Pb}(\mathrm{II}), \mathrm{Cu}(\mathrm{II})$, and $\mathrm{Hg}$ (II) ions can be identified at potentials of $0.774,0.578,0.109$ and $0.24 \mathrm{~V}$, respectively, which is not seen for the rest of the electrodes, wherein $\mathrm{Cd}$ (II) and $\mathrm{Pb}$ (II) peaks have merged together to form one broad peak thus indicating their inferior performances. Therefore, RGO/ $\mathrm{NiWO}_{4}$ nanocomposite electrodes seem to be a suitable electrode system for heavy metal ions detection.

Optimization of experimental conditions. Two parameters, namely, deposition potential and deposition time play a key role in achieving best sensitivity while detection of the metal ions. Therefore, a study on the effect of the deposition potential on the peak current for a fixed time duration (120 s deposition time) was conducted in the voltage range from 0 to $1.4 \mathrm{~V}$ in $0.1 \mathrm{M}$ acetate buffer ( $\mathrm{pH} 5.0$ ) for $\mathrm{Cu}$ (II) and $\mathrm{Pb}$ (II) ions and the results are shown in Fig. 4a. At lower deposition potentials, 0-0.4 V, hardly any peak current was observed, further increase in deposition potential led to increasing in peak current till $1.2 \mathrm{~V}$. Although, at $1.2 \mathrm{~V}$, higher peak current for $\mathrm{Cu}$ (II) and $\mathrm{Pb}$ (II) ions was observed, however, $\mathrm{H}_{2}$ evolution was also accompanied. In order to avoid the competitive generation of $\mathrm{H}_{2}$ and codeposition of other metal ions while analysis of complex aqueous media, $1.0 \mathrm{~V}$ was chosen as the optimized deposition potential. The difference in peak current values observed for different metal ions may be attributed to the different standard potentials of the respective metals. Deposition time can play a crucial role in determining the detection limit and sensitivity; hence variation in deposition time was studied. The deposition time was varied from $20-140 \mathrm{~s}$ at $1.0 \mathrm{~V}$ for $\mathrm{Cu}$ (II) and $\mathrm{Pb}$ (II) ions and the results are shown in Fig. $4 \mathrm{~b}$. The peak current increased with increase in deposition time, this is due to the increased amount of ions on the electrode surface. Although increasing the deposition time improved the sensitivity, but due to saturation of electrode surface, the upper detection limit at high metal ion concentrations may be lowered. ${ }^{28}$ Therefore, $120 \mathrm{~s}$ was chosen as optimized deposition time to achieve a lower detection limit.
Stripping behaviour toward $\mathrm{Cd}(\mathrm{II}), \mathrm{Pb}$ (II), $\mathrm{Cu}(\mathrm{II})$, and $\mathrm{Hg}$ (II) ions. To understand the stripping behaviour of metal ions, individual detection of $\mathrm{Cd}$ (II), $\mathrm{Pb}$ (II), $\mathrm{Cu}$ (II) and $\mathrm{Hg}$ (II) ions at $\mathrm{RGO} / \mathrm{NiWO}_{4}$ nanocomposite electrode using DPASV was performed. The limit of detection (LOD), sensitivity and correlation coefficients were determined for individual ions by varying the concentration of metal ions from 0.1 to $2.0 \mu \mathrm{M}$. In Fig. 5, the peak current increased linearly with increasing the metal ion concentration regardless of the type of the metal ion. Fig. 5a showed the DPASV response of Cd(II) ion at different concentrations in the range of 0.1 to $2.0 \mu \mathrm{M}$, where the well-defined peak was observed. From the calibration plot, the linear equation $i / \mathrm{mA}=0.5419+0.1145 C(\mu \mathrm{M})$ with the correlation coefficient of 0.9978 (inset of Fig. 5a) was obtained and LOD was calculated to be $4.7 \times 10^{-10} \mathrm{M}$ ( $3 \sigma$ method). The DPASV response of $\mathrm{Pb}$ (II) ions over a concentration range of 0.1 to $2.0 \mu \mathrm{M}$ was measured and the results are shown in Fig. 5b. From the calibration plot, the linear equation was $i / \mathrm{mA}=0.5327+$ $0.03412 C(\mu \mathrm{M})$, with the correlation coefficient of 0.9510 (inset of Fig. 5b) and LOD was calculated to be $3.8 \times 10^{-10} \mathrm{M}(3 \sigma$ method). The DPASV response of $\mathrm{Cu}(\mathrm{II})$ ions over a concentration range from 0.1 to $2.0 \mu \mathrm{M}$ is shown in Fig. 5c. From the calibration plot, the linear equation was $i / \mathrm{mA}=1.6169+$ $0.0407 C(\mu \mathrm{M})$, with the correlation coefficient of 0.9986 (inset of Fig. 5c) and LOD was calculated to be $4.4 \times 10^{-10} \mathrm{M}(3 \sigma$ method). The DPASV response of $\mathrm{Hg}$ (II) ions over a concentration range from 0.1 to $2.0 \mu \mathrm{M}$ is shown in Fig. $5 \mathrm{~d}$. From the calibration plot, the linear equation was $i / \mathrm{mA}=1.0549+$ $0.0683 C(\mu \mathrm{M})$, with the correlation coefficient of 0.9968 (inset of Fig. 5d) and LOD was calculated to be $2.8 \times 10^{-10} \mathrm{M}(3 \sigma$ method). One common observation made for all the heavy metal ions detection is that with the increase in the metal ion concentration, the peak intensity increases along with a positive shift in the peak potential. This phenomenon of peak shift is common as adsorption product tends to shift the peak potential positively. ${ }^{29}$ For further understanding, we performed cyclic voltammetry in an aqueous solution of $0.1 \mathrm{M} \mathrm{KCl}$ containing $5 \mathrm{mM} \mathrm{Fe}(\mathrm{CN})_{6}{ }^{3-}$ in the voltage range of $-0.1 \mathrm{~V}$ to $0.6 \mathrm{~V}$ with scan rate varying from 10 to $100 \mathrm{mV} \mathrm{s}^{-1}$. The results are shown in Fig. S4 in ESI. $\dagger$ It is clear that as the scan rate increases, the anodic and cathodic peak current increases linearly (see Fig. S4a†). A plot of anodic and cathodic peak current versus
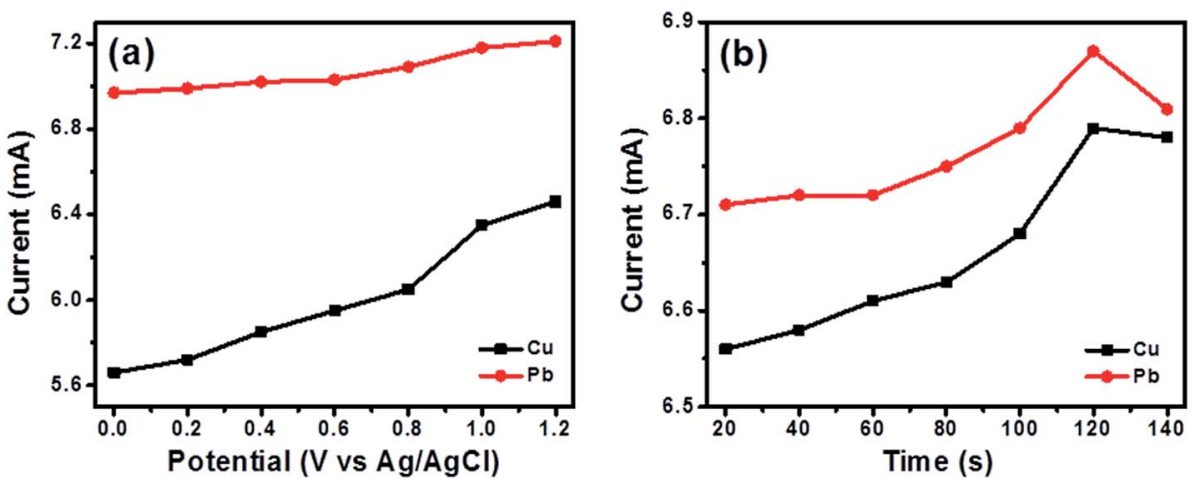

Fig. 4 Variation in (a) deposition potential and (b) deposition time for $\mathrm{Cu}(॥)$ and $\mathrm{Pb}(॥)$ ions using DPASV. Electrolyte: $0.1 \mathrm{M}$ acetate buffer (pH 5.0). 

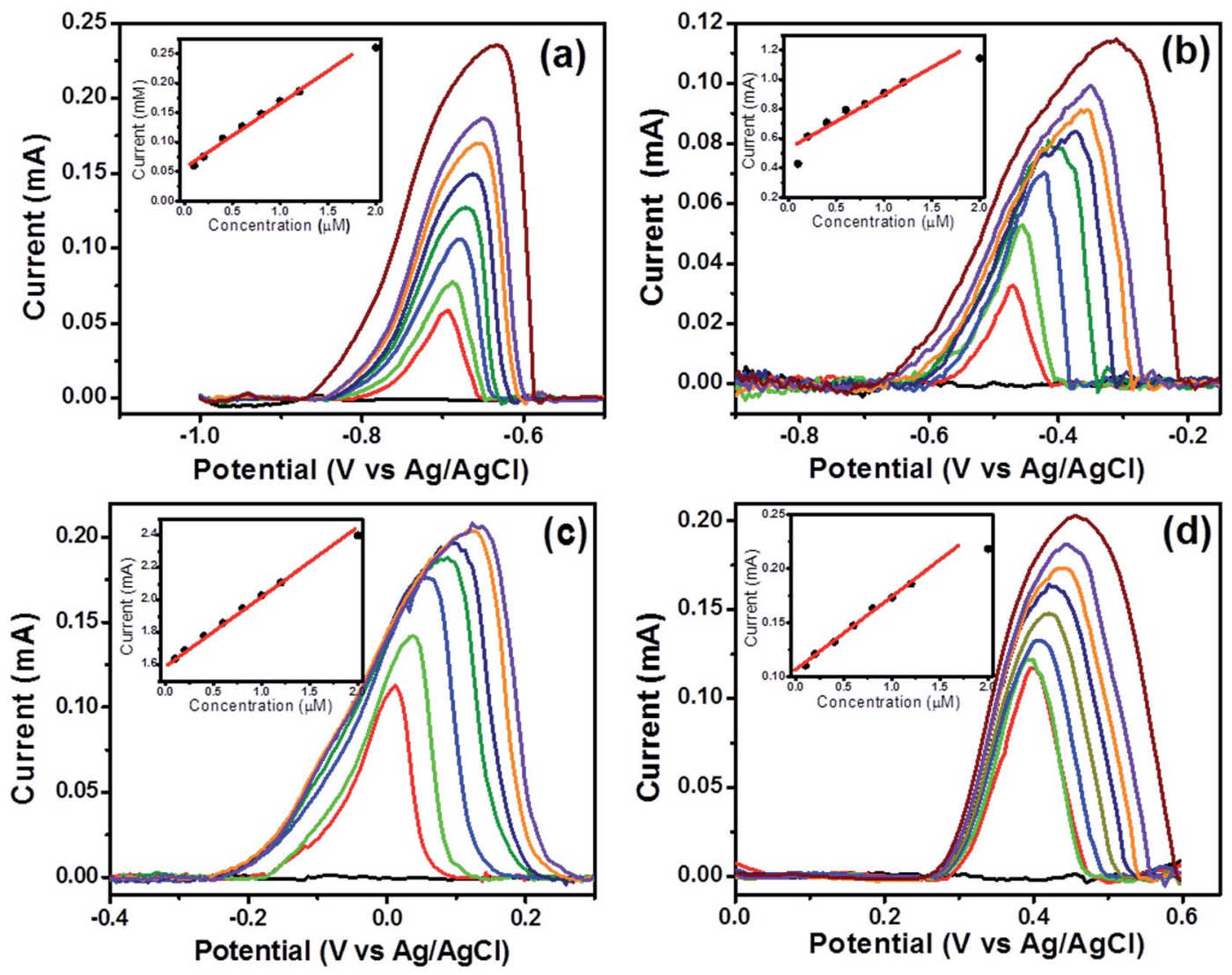

Fig. 5 DPASV response of $\mathrm{RGO} / \mathrm{NiWO}_{4}$ nanocomposite recorded at $1.0 \mathrm{~V}$ for $120 \mathrm{~s}$ for change in concentration of individual (a) $\mathrm{Cd}(॥)$ (b) $\mathrm{Pb}(॥)$ (c) $\mathrm{Cu}(I)$ and (d) $\mathrm{Hg}($ II) ions with inset showing respective calibration plot. Electrolyte: $0.1 \mathrm{M}$ acetate buffer $(\mathrm{pH} 5.0)$.

scan rate is also shown in Fig. S4b. $\dagger$ A linear trend indicates that this process is surface confined and thus adsorption controlled process. Further, the sensitivity, LOD and correlation coefficients suggested that $\mathrm{RGO} / \mathrm{NiWO}_{4}$ nanocomposite electrode can potentially serve as a good candidate for the determination of heavy metal ions.

Evaluation of mutual interferences. After evaluating the individual stripping behaviour of heavy metal ions, the simultaneous analysis was performed to understand their interference effect, if any. For simultaneous determination of $\mathrm{Cu}$ (II) and $\mathrm{Hg}$ (II) ions concentration was varied and results are shown in Fig. 6. Well-defined peaks of $\mathrm{Cu}$ (II) and $\mathrm{Hg}$ (II) ions were observed for all concentrations as shown in Fig. $6 \mathrm{a}$ and the peak currents of the both analyte ions increased with the increasing their respective concentrations. The resulting calibration plots for both the ions are shown in Fig. 6b, which is linear over the range from 0.2 to $0.7 \mu \mathrm{M}$. From the calibration plot, the linear equations where $i / \mathrm{mA}=0.8899+0.1174 C(\mu \mathrm{M})$ and $i / \mathrm{mA}=$ $0.9794+0.1245(\mu \mathrm{M})$, with the correlation coefficients of 0.9963 and 0.9971 and LOD was calculated to be $1.1 \times 10^{-10} \mathrm{M}$ and $1.2 \times 10^{-10} \mathrm{M}$ for $\mathrm{Cu}(\mathrm{II})$ and $\mathrm{Hg}$ (II) ions, respectively. During individual analysis of $\mathrm{Cu}$ (II) and $\mathrm{Hg}$ (II) ions, the sensitivity obtained $w \quad 0.0407 \quad \mathrm{~mA} \mu \mathrm{M}^{-1} \mathrm{~cm}^{-2}$ for $\mathrm{Cu}(\mathrm{II})$ ions and $0.0683 \mathrm{~mA} \mu \mathrm{M}^{-1} \mathrm{~cm}^{-2}$ for $\mathrm{Hg}$ (II) ions, however, in simultaneous analysis, the sensitivity obtained was 0.1174 and $0.1245 \mathrm{~mA} \mu \mathrm{M}^{-1} \mathrm{~cm}^{-2}$, respectively (see Table S1, ESI $\dagger$ ). These results are encouraging as there is a good separation between $\mathrm{Cu}(\mathrm{II})$ and $\mathrm{Hg}$ (II) ions peaks ruling out the formation of intermetallic compounds from these metals which are the case with many electrode systems. ${ }^{15,30-32}$ This result is attributed to the highly porous structure of $\mathrm{RGO} / \mathrm{NiWO}_{4}$ nanocomposite which lowered oxidation overpotential of each metal ions. ${ }^{29,31,33}$

Further, simultaneous analysis of three ions namely Cd(II), $\mathrm{Cu}(\mathrm{II})$ and $\mathrm{Hg}$ (II) ions was performed and results indicated existence of individual peaks for each ion in DPASV response as demonstrated in Fig. 7a and the peak currents of the three analyte ions increased with the increasing their respective concentrations. The correlation coefficients for $\mathrm{Cd}(\mathrm{II}), \mathrm{Cu}(\mathrm{II})$ and $\mathrm{Hg}$ (II) ions were obtained as 0.9905, 0.9954 and 0.9975, respectively from Fig. $7 \mathrm{~b}$. The sensitivity and LOD were obtained as $0.0622,0.1411$ and $0.1652 \mathrm{~mA} \mathrm{\mu M}^{-1} \mathrm{~cm}^{-2}$ and $1.2 \times 10^{-10}$, $1.16 \times 10^{-10}$ and $1.36 \times 10^{-10} \mathrm{M}$ for $\mathrm{Cd}(\mathrm{II}), \mathrm{Cu}$ (II) and $\mathrm{Hg}$ (II) ions respectively (see Table S1, ESI $\dagger$ ). This result was likely due to the formation of $\mathrm{Cd}-\mathrm{Cu}^{34}$ and $\mathrm{Cd}-\mathrm{Hg}^{33}$ intermetallic alloy which increased the sensitivity for $\mathrm{Cu}$ (II) and $\mathrm{Hg}$ (II) ions. Similar study was performed for $\mathrm{Pb}$ (II), $\mathrm{Cu}$ (II) and $\mathrm{Hg}$ (II) ions and well-defined peaks were observed in DPASV response for each ion as shown in Fig. 7c and sensitivity and LOD from simultaneous detection were found as $0.0857,0.07432,0.0809 \mathrm{~mA} \mu \mathrm{M}^{-1} \mathrm{~cm}^{-2}$ and $2.04 \times 10^{-10}, 1.11 \times 10^{-10}$ and $1.92 \times 10^{-10} \mathrm{M}$ for $\mathrm{Pb}(\mathrm{II}), \mathrm{Cu}$ (II) and $\mathrm{Hg}$ (II) ions respectively from Fig. $7 \mathrm{~d}$. The correlation coefficients for $\mathrm{Pb}$ (II), $\mathrm{Cu}$ (II) and $\mathrm{Hg}$ (II) ions were obtained as 0.9952 , 

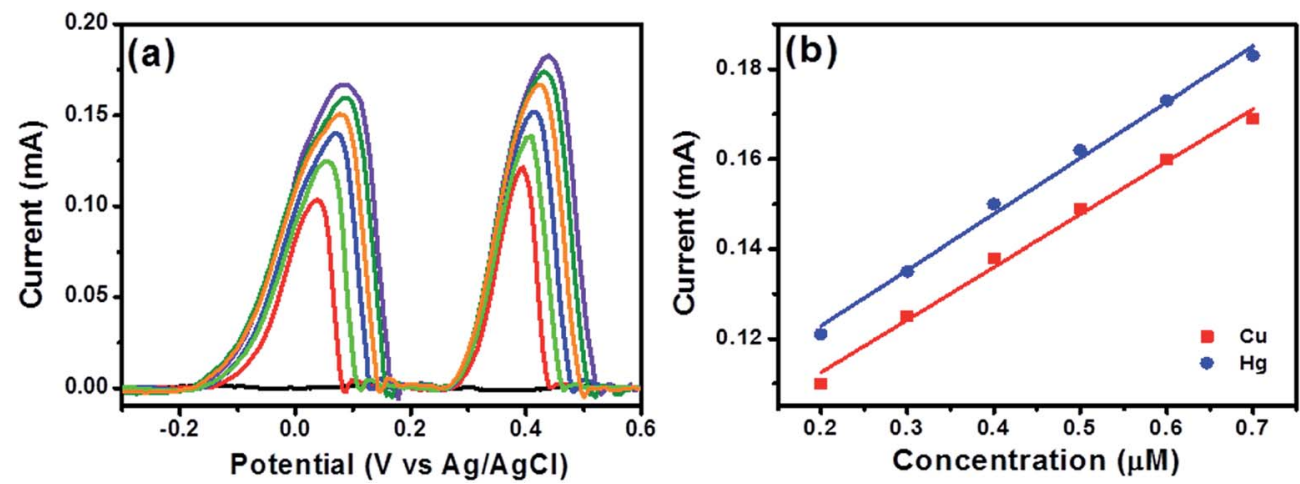

Fig. 6 DPASV response of $\mathrm{RGO} / \mathrm{NiWO}_{4}$ nanocomposite recorded at $1.0 \mathrm{~V}$ for $120 \mathrm{~s}$ for simultaneous change in concentration of (a) Cu(॥) and $\mathrm{Hg}($ II) ions from 0.2 to $0.7 \mu \mathrm{M}$ for each metal ion with their calibration plots (b). Electrolyte: $0.1 \mathrm{M}$ acetate buffer (pH 5.0).

0.9983 and 0.9962 , respectively. In presence of $\mathrm{Pb}(\mathrm{II})$, it is clear that the sensitivity of $\mathrm{Cu}(\mathrm{II})$ and $\mathrm{Hg}$ (II) has decreased probably due to the formation of an intermetallic alloy.

After simultaneous analysis of two and three metal ions, simultaneous analysis of all the fours ions, $\mathrm{Cd}(\mathrm{II}), \mathrm{Pb}(\mathrm{II}), \mathrm{Cu}(\mathrm{II})$, and $\mathrm{Hg}$ (II) ions at increasing concentrations under the optimal experimental conditions were performed and results are shown in Fig. 8 and the peak currents of all the analyte ions increased with the increasing their respective concentrations. Coexistence of individual peaks in DPASV response for $\mathrm{Cd}(\mathrm{II}), \mathrm{Pb}(\mathrm{II}), \mathrm{Cu}(\mathrm{II})$, and $\mathrm{Hg}$ (II) ions in the simultaneous detection of different concentrations is observed which is remarkable (see Fig. 8a) and this makes the simultaneous or the selective detection of metal ions on this electrode surface feasible. The correlation coefficients for $\mathrm{Cd}(\mathrm{II}), \mathrm{Pb}$ (II), $\mathrm{Cu}$ (II) and $\mathrm{Hg}$ (II) ions were obtained as $0.995,0.984,0.976$ and 0.965 , respectively from Fig. $8 \mathrm{~b}$. The LOD was found to be $1.015 \times 10^{-10}, 1.839 \times 10^{-10}$, $2.269 \times 10^{-10}$ and $2.789 \times 10^{-10} \mathrm{M}$, respectively. These LOD values are very well below the guideline value given by the World Health Organization (WHO). Also, the sensitivity values for
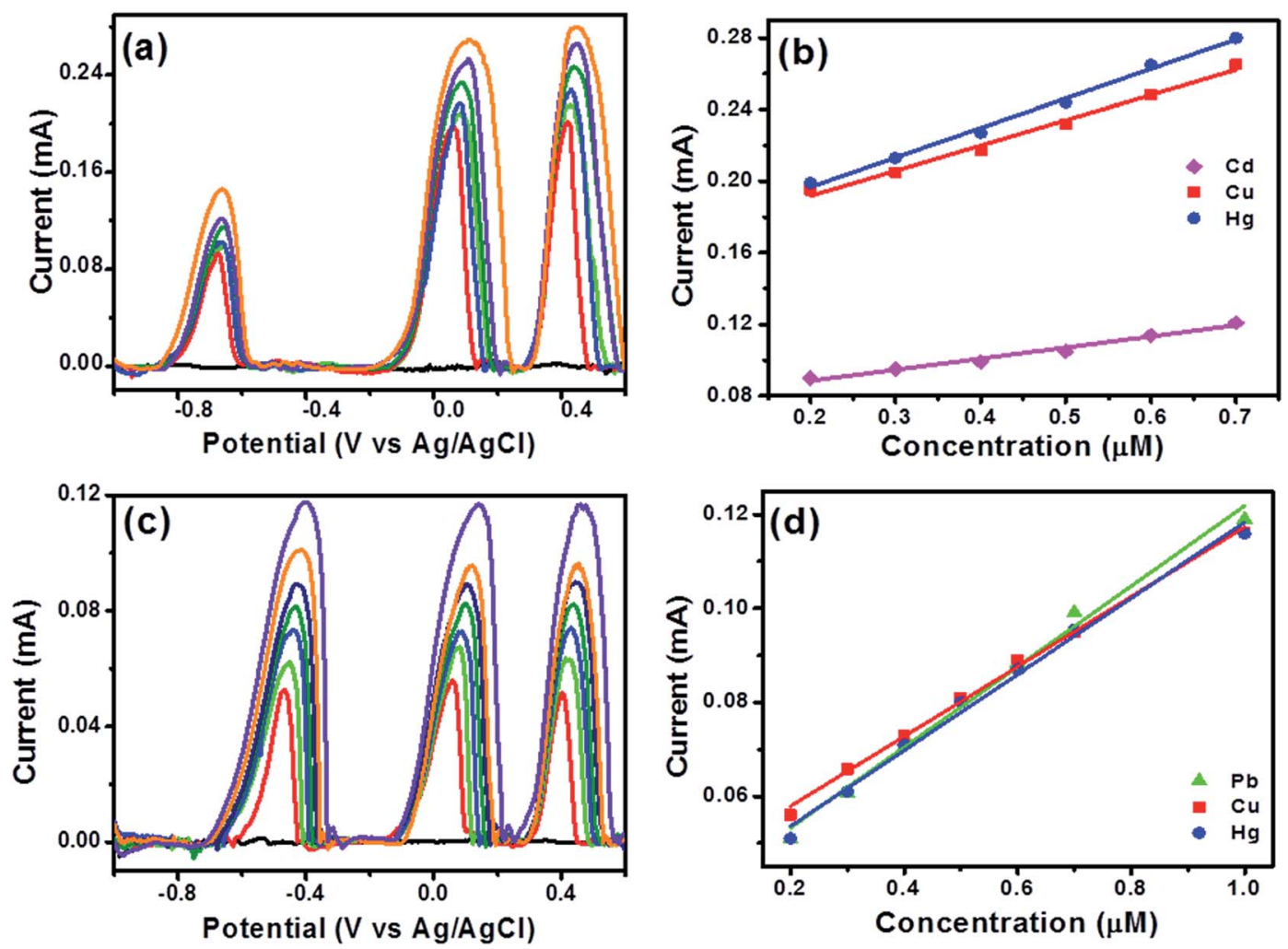

Fig. 7 DPASV response of $\mathrm{RGO} / \mathrm{NiWO}_{4}$ nanocomposite recorded at $1.0 \mathrm{~V}$ for $120 \mathrm{~s}$ for simultaneous change in concentration of (a) $\mathrm{Cd}($ (I), Cu(॥) and $\mathrm{Hg}(॥)$ ions (c) $\mathrm{Pb}(॥), \mathrm{Cu}(॥)$ and $\mathrm{Hg}(॥)$ ions from 0.2 to $0.7 \mu \mathrm{M}$ for each metal ion with their respective calibration plots (b) and (d). Electrolyte: $0.1 \mathrm{M}$ acetate buffer $(\mathrm{pH}$ 5.0). 

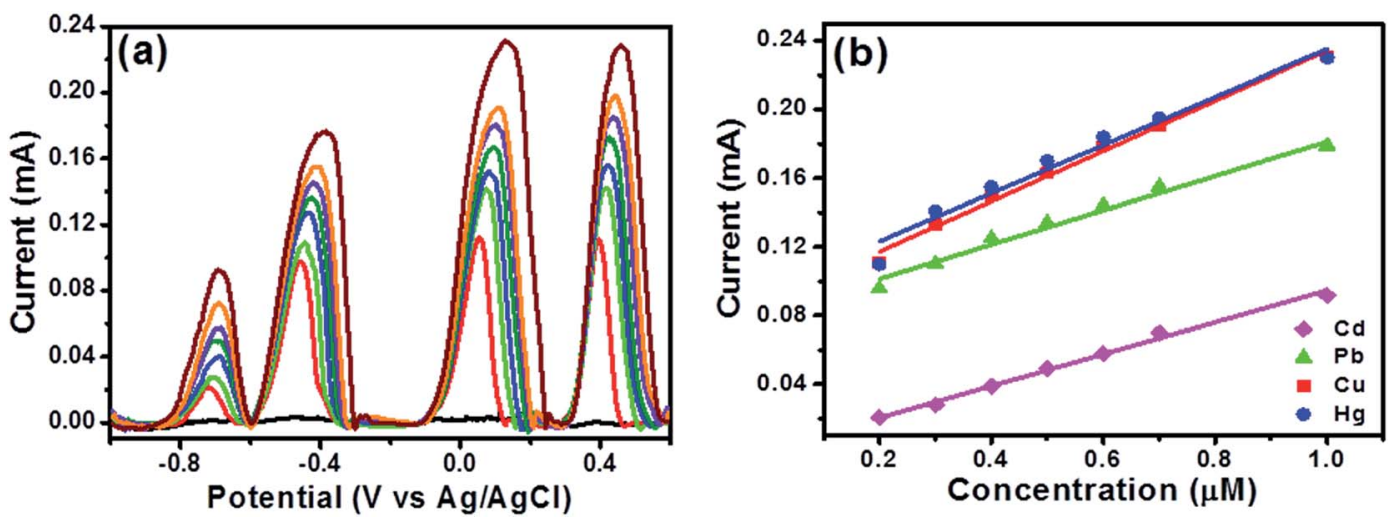

Fig. 8 DPASV response of $\mathrm{RGO} / \mathrm{NiWO}_{4}$ nanocomposite recorded at $1.0 \mathrm{~V}$ for $120 \mathrm{~s}$ for simultaneous change in concentration of (a) $\mathrm{Cd}(\Perp)$, $\mathrm{Pb}(\mathrm{I})$, $\mathrm{Cu}(\mathrm{II})$ and $\mathrm{Hg}(\mathrm{II})$ ions from 0.2 to $1.0 \mu \mathrm{M}$ for each metal ion with their calibration plots (b). Electrolyte: $0.1 \mathrm{M}$ acetate buffer (pH 5.0).

$\mathrm{Cd}$ (II), $\mathrm{Pb}$ (II), $\mathrm{Cu}$ (II) and $\mathrm{Hg}$ (II) ions is found to be $0.00998,0.0098$, $0.01465,0.01401 \mathrm{~mA} \mu \mathrm{M}^{-1} \mathrm{~cm}^{-2}$, respectively. It is clear that in presence of $\mathrm{Pb}$ (II), the sensitivity of $\mathrm{Cd}$ (II), $\mathrm{Cu}$ (II) and $\mathrm{Hg}$ (II) ions has decreased as seen in the Fig. $7 \mathrm{c}$. These results indicated that the interference may occur due to the formation of intermetallic alloys for the four metal ions, which affects the sensitivity and similar observations are made in studies with coexistence of four target metal ions $\mathrm{s}^{15}$ in literature as well and another reason being to the competitive adsorption of the heavy metal ions on the electrode surface. A comparison of LOD values of the proposed electrode with previously reported different electrodes for the determination of $\mathrm{Cd}(\mathrm{II}), \mathrm{Pb}$ (II), $\mathrm{Cu}$ (II), $\mathrm{Hg}$ (II) ions is provided in Table S2, ESI. $\dagger$ However, the best aspect of the proposed electrode is demonstrated in the next section where it has been tested in complex aqueous media.

Analysis of $\mathrm{Cd}$ (II), $\mathrm{Pb}$ (II), $\mathrm{Cu}$ (II), and $\mathrm{Hg}$ (II) ions in complex aqueous media. In order to evaluate the real application performance of the proposed electrode, we illustrate the use of $\mathrm{RGO} / \mathrm{NiWO}_{4}$ nanocomposite electrode in complex aqueous media. The electrode is employed for detection of heavy metal ions in carbonated drinks, milk and fruit juice samples which normally contain traceable amounts of $\mathrm{Cd}$ (II), $\mathrm{Pb}$ (II), $\mathrm{Cu}$ (II) and $\mathrm{Hg}$ (II) ions due to contamination which goes unnoticed. ${ }^{25,35}$ The DPASV responses of $\mathrm{RGO} / \mathrm{NiWO}_{4}$ nanocomposite electrode towards $\mathrm{Cd}(\mathrm{II}), \mathrm{Pb}$ (II), $\mathrm{Cu}$ (II) and $\mathrm{Hg}$ (II) ions in a carbonated drink, milk, and orange juice is shown in Fig. 9. These samples show the absence of toxic metal ions; however, upon addition of various metal ions, their signals were detected. As the concentrations of metal ions were increased, peak current also increased. Fig. 9a showed increase in peak current of four metal ions in carbonated drink. The correlation coefficients for $\mathrm{Cd}(\mathrm{II})$, $\mathrm{Pb}$ (II), $\mathrm{Cu}$ (II) and $\mathrm{Hg}$ (II) ions in carbonated drink were obtained as $0.9965,0.9999,0.9883$ and 0.9929 , respectively as shown in Fig. 9d. Also, LOD was found to be $1.11 \times 10^{-10}, 2.04 \times 10^{-10}$, $2.80 \times 10^{-10}$ and $3.05 \times 10^{-10} \mathrm{M}$, respectively, whereas the sensitivity was found to be $0.0008,0.0147,0.0202$ and $0.2192 \mathrm{~mA} \mu \mathrm{M}^{-1} \mathrm{~cm}^{-2}$, respectively. The detection of $\mathrm{Cd}$ (II), $\mathrm{Pb}$ (II), $\mathrm{Cu}$ (II) and $\mathrm{Hg}$ (II) ions in milk by adding the known amount of toxic metal ions was also performed. All four metal ions were successfully detected as seen in Fig. $9 \mathrm{~b}$ and the correlation coefficients were found to be $0.9993,0.9984,0.9983$ and 0.9927 , respectively as shown in Fig. 9e. LOD was found to be $3.83 \times 10^{-10}, 2.09 \times 10^{-10}, 1.74 \times 10^{-10}$ and $9.34 \times 10^{-10} \mathrm{M}$, respectively, whereas, the sensitivity was found to be 0.0027 , $0.0149,0.0125$ and $0.00671 \mathrm{~mA} \mu \mathrm{M}^{-1} \mathrm{~cm}^{-2}$, respectively. Additionally, orange juice as medium for heavy metal ions detection displayed four distinct peaks as shown in Fig. 9c and the correlation coefficients were found to be $0.9905,0.9999,0.9870$ and 0.9907 for $\mathrm{Cd}$ (II), $\mathrm{Pb}$ (II), $\mathrm{Cu}$ (II) and $\mathrm{Hg}$ (II) ions, respectively from the calibration plot (Fig. 9f). LOD was obtained as $2.72 \times$ $10^{-10}, 2.26 \times 10^{-10}, 2.04 \times 10^{-10}$ and $2.88 \times 10^{-10} \mathrm{M}$, respectively, whereas the sensitivity was found to be $0.0211,0.01634$, 0.1468 and $0.02073 \mathrm{~mA} \mu \mathrm{M}^{-1} \mathrm{~cm}^{-2}$, respectively. The above results clearly demonstrate that $\mathrm{RGO} / \mathrm{NiWO}_{4}$ nanocomposite is suitable electrode material for detection of heavy metal ions in complex aqueous media as well. The experiments were repeated six times with good reproducibility as the obtained relative standard deviations (RSDs) were all less than $4 \%$. Although the sensing properties of LOD and sensitivity at the RGO/NiWO nanocomposite are comparable with some work (see Table S2, ESI $\dagger$ ) reported previously, ${ }^{15,16,25,29}$ the electrode described here can provide selective and simultaneous analysis of four toxic heavy metal ions in water and complex aqueous media. The obtained sensing performance is good enough for implication in practice and as demonstrated it is not limited to water and can be extended to many practical applications with some standardization. Thus, the proposed nanocomposite electrode can successfully be used for simultaneous detection of toxic metal ions without any further modifications.

Stripping mechanism. To further understand the stripping mechanism of the proposed electrode, XPS analysis on the RGO/ $\mathrm{NiWO}_{4}$ nanocomposite electrode was performed before and after stripping. Initially, the electrode was subjected to 50 cycles and XPS was recorded (before) and DPASV was performed with four heavy metal ions in the solution and following that XPS was recorded (after). XPS spectra of the electrode before and after DPASV are provided in the ESI (Fig. S5 and S6 $\dagger$ ). The results indicate that the proposed electrode is stable and does not undergo any chemical modification during the cycling and DPASV measurements. In Fig. 10, XPS spectra collected of Cd 

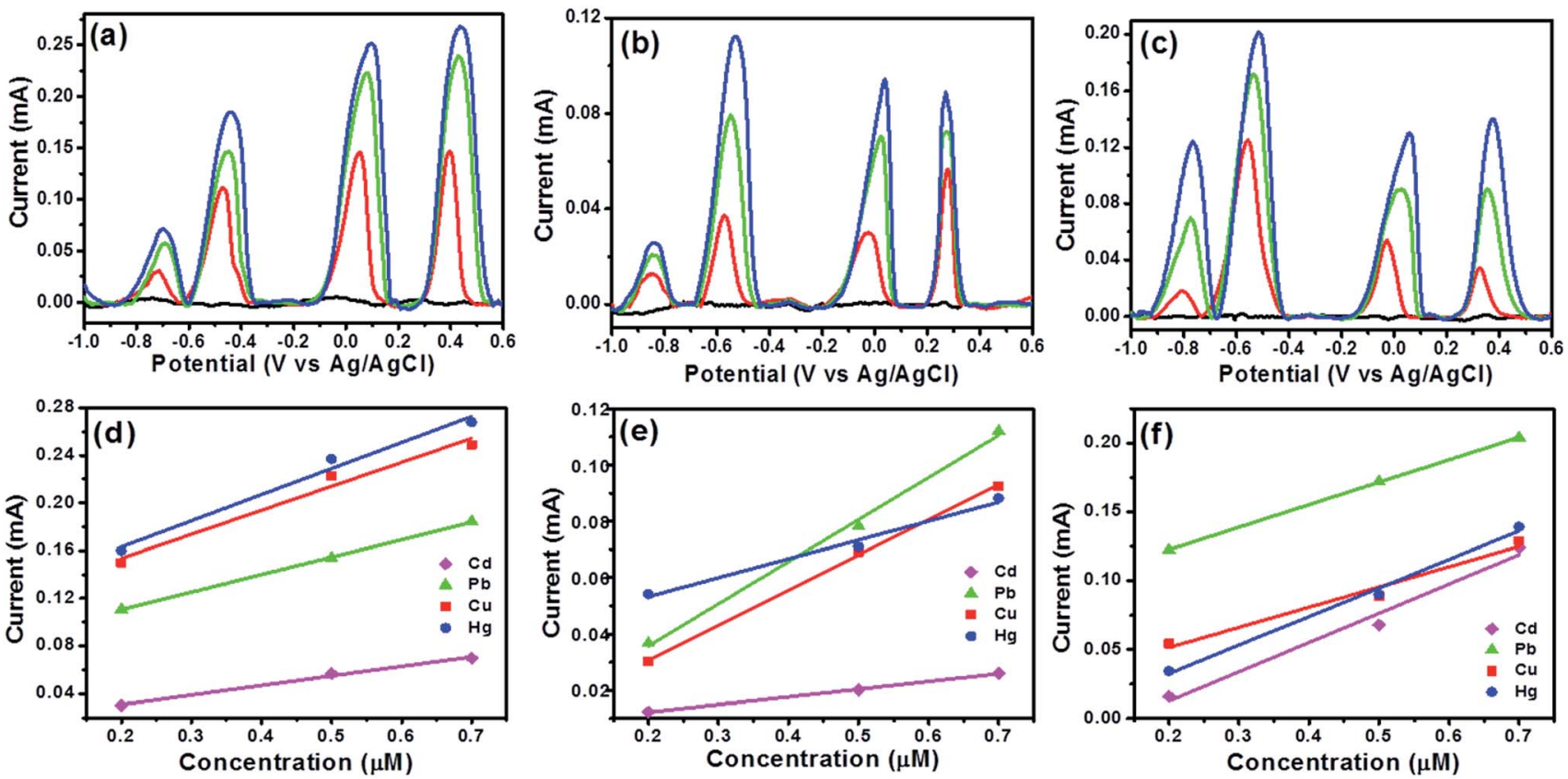

Fig. 9 DPASV response of $\mathrm{RGO} / \mathrm{NiWO}_{4}$ nanocomposite recorded at $1.0 \mathrm{~V}$ for $120 \mathrm{~s}$ for simultaneous detection of $\mathrm{Cd}(॥), \mathrm{Pb}(॥), \mathrm{Cu}(॥)$ and $\mathrm{Hg}(॥)$ ions in (a) carbonated drink (b) milk (c) orange juice from 0.2 to $0.7 \mu \mathrm{M}$ for each metal ion with their respective calibration curve (d-f). Electrolyte: $0.1 \mathrm{M}$ acetate buffer $(\mathrm{pH}$ 5.0).

$3 \mathrm{~d}, \mathrm{~Pb} 4 \mathrm{f}, \mathrm{Cu} 2 \mathrm{p}$ and $\mathrm{Hg} 4 \mathrm{f}$ levels are shown. The noise in the spectra is attributed to the low concentration of heavy metal ions. The XPS spectra for Cd 3d level (Fig. 10a) showed two broad peaks with binding energy values of 405.7 and $413.8 \mathrm{eV}$ for $\mathrm{Cd} 3 \mathrm{~d}_{5 / 2}$ and $\mathrm{Cd} 3 \mathrm{~d}_{3 / 2}$ core energy levels, respectively and the binding energy values corresponded to $\mathrm{Cd}(\mathrm{II})$. The two peaks
(Fig. 10b) at $139.2 \mathrm{eV}$ and $144.0 \mathrm{eV}$ for $\mathrm{Pb} 4 \mathrm{f}_{7 / 2}$ and $\mathrm{Pb} 4 \mathrm{f}_{5 / 2}$, respectively and the binding energy values corresponded to $\mathrm{Pb}(\mathrm{II})$. The XPS spectra for $\mathrm{Cu} 2 \mathrm{p}$ level (Fig. 10c) showed two broad peaks with binding energy values of 933.2 and $953.0 \mathrm{eV}$ for $\mathrm{Cu} 2 \mathrm{p}_{3 / 2}$ and $\mathrm{Cu} 2 \mathrm{p}_{1 / 2}$ core energy levels, respectively along with a satellite around $944.4 \mathrm{eV}$ confirming $\mathrm{Cu}(\mathrm{II})$. In Fig. 10d,
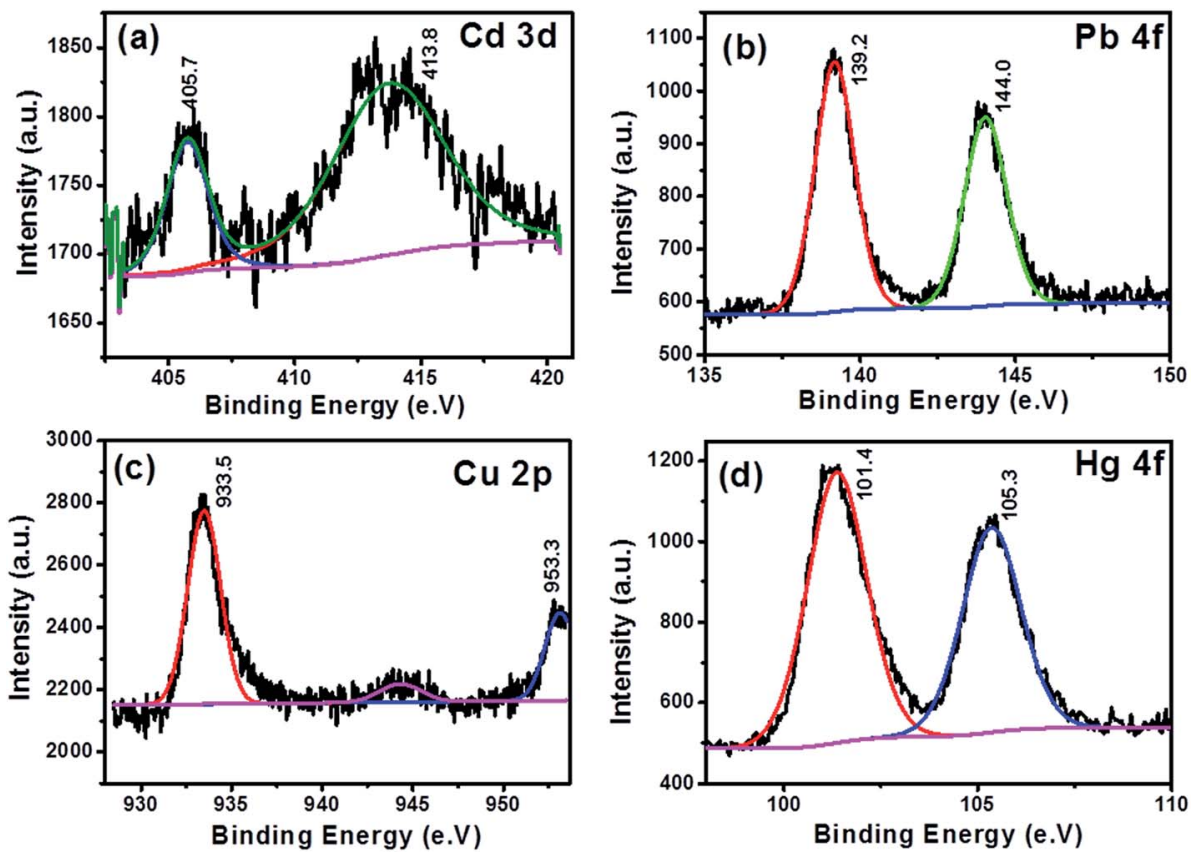

Fig. 10 XPS analysis of RGO/NiWO 4 nanocomposite electrode after cycling and DPASV with heavy metal ions: (a) $\mathrm{Cd} 3 \mathrm{~d}$, (b) Pb 4f, (c) $\mathrm{Cu} 2 \mathrm{p}$ and (d) $\mathrm{Hg} 4 \mathrm{f}$. 
XPS spectra of $\mathrm{Hg} 4 \mathrm{f}$ core level, $\mathrm{Hg} 4 \mathrm{f}_{7 / 2}$ and $\mathrm{Hg} 4 \mathrm{f}_{5 / 2}$ with their binding energy values as $101.4 \mathrm{eV}$ and $105.3 \mathrm{eV}$, respectively are shown and the binding energy values corresponded to $\mathrm{Hg}$ (II). Thus the above results indicate that there is no metal reduction or complex formation between the heavy metal ions and the proposed electrode. The advantage of $\mathrm{RGO} / \mathrm{NiWO}_{4}$ nanocomposite electrode is it has large surface area and pore volume as indicated by BET measurements Fig. S3 $\uparrow$ that provided high adsorption capacity for the electrode surface. The heavy metal ions get adsorbed on to the surface of the electrode and provide electrochemical detection. ${ }^{36}$ The adsorption mechanism is also supported by the CV study shown Fig. S4† wherein the peak current increases linearly as the scan rate is varied which support adsorption controlled process. XPS analysis along with the stripping peak current can provide some insight into the adsorption behaviour of the target heavy metal ions as the stripping peak current values are driven by the amount of target ions adsorbed onto the electrode surface. The basic principle for stripping being, the more target ion is adsorbed onto the surface of the electrode, the more will be released and thus increasing the stripping response. The signal from XPS analysis indicated $\mathrm{Cu}$ (II) $>\mathrm{Hg}$ (II) $>\mathrm{Pb}$ (II) $>\mathrm{Cd}$ (II) is the order of preferential adsorption of the heavy metal ion onto the proposed electrode. Though the peak intensities of $\mathrm{Cu}(\mathrm{II}), \mathrm{Hg}$ (II) and $\mathrm{Pb}$ (II) are comparable and Cd(II) with a very weak signal thus indicating the least adsorption capacity of the electrode which is consistent with the DPASV electrochemical measurements.

\section{Conclusions}

The present study demonstrates a novel synthesis of RGO/ $\mathrm{NiWO}_{4}$ nanocomposite by the one-pot hydrothermal method and its application in selective and simultaneous detection of heavy metal ions by DPASV. The results suggest that the combination of RGO with binary metal oxide exhibits better and well-resolved peaks of $\mathrm{Cd}(\mathrm{II}), \mathrm{Pb}$ (II), $\mathrm{Cu}$ (II), and $\mathrm{Hg}$ (II) ions during simultaneous detection as compared to $\mathrm{NiWO}_{4}$ NPs and RGO sheets. The incorporation of $\mathrm{NiWO}_{4}$ NPs into RGO sheets not only enhances the specific surface area and the electrical conductivity of the nanocomposite but also improves the electrochemical catalytic activity toward the selectivity of heavy metal ion detection. There is no mutual inference of the metal ions observed in our study, which demonstrates the better catalytic property of $\mathrm{RGO} / \mathrm{NiWO}_{4}$ nanocomposite towards all the four heavy metal ions investigated. LOD was well below the recommended value provided by the World Health Organization (WHO). The nanocomposite developed here is not only effective for simultaneous determination of $\mathrm{Cd}(\mathrm{II}), \mathrm{Pb}(\mathrm{II}), \mathrm{Cu}(\mathrm{II})$, and $\mathrm{Hg}$ (II) ions in their aqueous solutions, but also in the complex media such as carbonated drinks, milk and fruit juices. XPS analysis of target metal ions on the electrode indicate preferential adsorption of heavy metal ions in the following order $\mathrm{Cu}$ (II), $\mathrm{Hg}$ (II), $\mathrm{Pb}$ (II) and least being $\mathrm{Cd}$ (II). The study thus suggests the optimal $\mathrm{RGO} / \mathrm{NiWO}_{4}$ nanocomposite developed here to be an ideal candidate for heavy metal ions detection by electrochemical stripping method.

\section{Conflicts of interest}

There are no conflicts to declare.

\section{Acknowledgements}

T. B. thanks the Department of Science \& Technology (DST), Government of India, for SERB-Start-up Research Grant (Young Scientist) (SB/FT/CS-060/2012) and DST-INSPIRE Fellowship (DST/INSPIRE/04/2014/002251; IFA13/MS-36) for the financial support. Authors thank Mr Prashant Kumar Gupta for the help with XPS measurements. This work was supported by Centre of Nanosciences, Indian Institute of Technology, Kanpur.

\section{References}

1 P. B. Kelter, J. Grundman, D. S. Hage, J. D. Carr and C. M. Castro-Acuna, A Discussion of Water Pollution in the United States and Mexico; with High School Laboratory Activities for the Analysis of Lead, Atrazine, and Nitrate, $J$. Chem. Educ., 1997, 74(12), 1413.

2 M. Melgar, B. Míguez, M. Pérez, M. García, M. Fernández and M. Vidal, Heavy metals (Cd, Pb, Fe, Mn, Zn, Cu) in drinking water as toxicological indicators, J. Environ. Sci. Health, Part A: Environ. Sci. Eng. Toxic Hazard. Subst. Control, 1997, 32(3), 687-697.

3 G. Wu, H. Kang, X. Zhang, H. Shao, L. Chu and C. Ruan, A critical review on the bio-removal of hazardous heavy metals from contaminated soils: issues, progress, ecoenvironmental concerns and opportunities, J. Hazard. Mater., 2010, 174(1-3), 1-8.

4 H. L. Needleman and D. Bellinger, The Health Effects of Low Level Exposure to Lead, Annu. Rev. Public Health, 1991, 12(1), 111-140.

5 V. K. Gupta, M. R. Ganjali, P. Norouzi, H. Khani, A. Nayak and S. Agarwal, Electrochemical Analysis of Some Toxic Metals by Ion-Selective Electrodes, Crit. Rev. Anal. Chem., 2011, 41(4), 282-313.

6 C. Gao, X.-Y. Yu, R.-X. Xu, J.-H. Liu and X.-J. Huang, AlOOHReduced Graphene Oxide Nanocomposites: One-Pot Hydrothermal Synthesis and Their Enhanced Electrochemical Activity for Heavy Metal Ions, ACS Appl. Mater. Interfaces, 2012, 4(9), 4672-4682.

7 G. March, T. Nguyen and B. Piro, Modified Electrodes Used for Electrochemical Detection of Metal Ions in Environmental Analysis, Biosensors, 2015, 5(2), 241.

8 F. J. Morin, Electrical Properties of NiO, Phys. Rev., 1954, 93(6), 1199-1204.

9 V. Biju and M. Abdul Khadar, DC conductivity of consolidated nanoparticles of NiO, Mater. Res. Bull., 2001, 36(1), 21-33.

10 A. S. Bhatt, D. K. Bhat, M. S. Santosh and C.-w. Tai, Chitosan/ NiO nanocomposites: a potential new dielectric material, $J$. Mater. Chem., 2011, 21(35), 13490-13497.

11 B. Moreno, E. Chinarro, M. T. Colomer and J. R. Jurado, Combustion Synthesis and Electrical Behavior of 
Nanometric $\beta$-NiMoO4, J. Phys. Chem. C, 2010, 114(10), 4251-4257.

12 W. Wang, L. Hu, J. Ge, Z. Hu, H. Sun, H. Sun, H. Zhang, H. Zhu and S. Jiao, In Situ Self-Assembled FeWO4/ Graphene Mesoporous Composites for Li-Ion and Na-Ion Batteries, Chem. Mater., 2014, 26(12), 3721-3730.

13 V. D. Nithya, R. Kalai Selvan, D. Kalpana, L. Vasylechko and C. Sanjeeviraja, Synthesis of Bi2WO6 nanoparticles and its electrochemical properties in different electrolytes for pseudocapacitor electrodes, Electrochim. Acta, 2013, 109, 720-731.

14 R. Kumar, P. K. Gupta, A. Agrawal, R. K. Nagarale and A. Sharma, Hydrothermally Synthesized Reduced Graphene Oxide-NiWO4 Nanocomposite for Lithium-Ion Battery Anode, J. Electrochem. Soc., 2017, 164(4), A785-A795.

15 Y. Wei, C. Gao, F.-L. Meng, H.-H. Li, L. Wang, J.-H. Liu and X.-J. Huang, SnO2/Reduced Graphene Oxide Nanocomposite for the Simultaneous Electrochemical Detection of Cadmium(II), Lead(II), Copper(II), and Mercury(II): An Interesting Favorable Mutual Interference, J. Phys. Chem. C, 2011, 116(1), 1034-1041.

16 Y.-L. Xie, S.-Q. Zhao, H.-L. Ye, J. Yuan, P. Song and S.-Q. Hu, Graphene/CeO2 hybrid materials for the simultaneous electrochemical detection of cadmium(II), lead(II), copper(II), and mercury(II), J. Electroanal. Chem., 2015, 757, 235-242.

17 S. Xiong, B. Yang, D. Cai, G. Qiu and Z. Wu, Individual and Simultaneous Stripping Voltammetric and Mutual Interference Analysis of $\mathrm{Cd} 2+, \mathrm{Pb} 2+$ and $\mathrm{Hg} 2+$ with Reduced Graphene Oxide-Fe3O4 Nanocomposites, Electrochim. Acta, 2015, 185, 52-61.

18 P. M. Lee, Z. Chen, L. Li and E. Liu, Reduced graphene oxide decorated with tin nanoparticles through electrodeposition for simultaneous determination of trace heavy metals, Electrochim. Acta, 2015, 174, 207-214.

19 B. C. Janegitz, L. C. S. Figueiredo-Filho, L. H. MarcolinoJunior, S. r. P. N. Souza, E. R. Pereira-Filho and O. Fatibello-Filho, Development of a carbon nanotubes paste electrode modified with crosslinked chitosan for cadmium(II) and mercury(II) determination, J. Electroanal. Chem., 2011, 660(1), 209-216.

20 X. Xu, G. Duan, Y. Li, G. Liu, J. Wang, H. Zhang, Z. Dai and W. Cai, Fabrication of Gold Nanoparticles by Laser Ablation in Liquid and Their Application for Simultaneous Electrochemical Detection of $\mathrm{Cd} 2+, \mathrm{Pb} 2+, \mathrm{Cu} 2+, \mathrm{Hg} 2+$, ACS Appl. Mater. Interfaces, 2014, 6(1), 65-71.

21 W. Yantasee, Y. Lin, G. E. Fryxell and B. J. Busche, Simultaneous detection of cadmium, copper, and lead using a carbon paste electrode modified with carbamoylphosphonic acid self-assembled monolayer on mesoporous silica (SAMMS), Anal. Chim. Acta, 2004, 502(2), 207-212.

22 Y. Wei, R. Yang, J.-H. Liu and X.-J. Huang, Selective detection toward $\mathrm{Hg}$ (II) and $\mathrm{Pb}(\mathrm{II})$ using polypyrrole/carbonaceous nanospheres modified screen-printed electrode, Electrochim. Acta, 2013, 105, 218-223.
23 Z. Jin, M. Yang, S.-H. Chen, J.-H. Liu, Q.-X. Li and X.-J. Huang, Tin Oxide Crystals Exposed by Low-Energy $\{110\}$ Facets for Enhanced Electrochemical Heavy Metal Ions Sensing: X-ray Absorption Fine Structure Experimental Combined with Density-Functional Theory Evidence, Anal. Chem., 2017, 89(4), 2613-2621.

24 P. Zhang, Y. Wang and D. Zhang, Removal of Nd(III), Sr(II), and $\mathrm{Rb}(\mathrm{I})$ Ions from Aqueous Solution by ThiacalixareneFunctionalized Graphene Oxide Composite as an Adsorbent, J. Chem. Eng. Data, 2016, 61(10), 3679-3691.

25 P. Veerakumar, V. Veeramani, S.-M. Chen, R. Madhu and S.-B. Liu, Palladium Nanoparticle Incorporated Porous Activated Carbon: Electrochemical Detection of Toxic Metal Ions, ACS Appl. Mater. Interfaces, 2016, 8(2), 13191326.

26 R. Kumar, K. Jahan, R. K. Nagarale and A. Sharma, Nongassing Long-Lasting Electro-osmotic Pump with Polyaniline-wrapped Aminated Graphene Electrodes, ACS Appl. Mater. Interfaces, 2015, 7(1), 593-601.

27 U. Nithiyanantham, S. R. Ede, S. Anantharaj and S. Kundu, Self-Assembled NiWO4 Nanoparticles into Chain-like Aggregates on DNA Scaffold with Pronounced Catalytic and Supercapacitor Activities, Cryst. Growth Des., 2015, 15(2), 673-686.

28 X. Gao, W. Wei, L. Yang and M. Guo, Carbon Nanotubes/ Poly(1,2-diaminobenzene) Nanoporous Composite Film Electrode Prepared by Multipulse Potentiostatic Electropolymerisation and Its Application to Determination of Trace Heavy Metal Ions, Electroanalysis, 2006, 18(5), 485-492.

29 R. Madhu, K. V. Sankar, S.-M. Chen and R. K. Selvan, Ecofriendly synthesis of activated carbon from dead mango leaves for the ultrahigh sensitive detection of toxic heavy metal ions and energy storage applications, RSC Adv., 2013, 4(3), 1225-1233.

30 J. Pei, M.-L. Tercier-Waeber and J. Buffle, Simultaneous Determination and Speciation of Zinc, Cadmium, Lead, and Copper in Natural Water with Minimum Handling and Artifacts, by Voltammetry on a Gel-Integrated Microelectrode Array, Anal. Chem., 2000, 72(1), 161-171.

31 H. Chan, A. Butler, D. M. Falck and M. S. Freund, Artificial Neural Network Processing of Stripping Analysis Responses for Identifying and Quantifying Heavy Metals in the Presence of Intermetallic Compound Formation, Anal. Chem., 1997, 69, 2373-2378.

32 A. H. I. Ben-Bassat and A. Azrad, Intermetallic compounds formed in mixed (complex) amalgams-I. The systems: copper-mercury, zinc-mercury and copper-zinc-mercury, Electrochim. Acta, 1978, 23(1), 63-69.

33 J. r. Schiewe, K. B. Oldham, J. C. Myland, A. M. Bond, V. A. Vicente-Beckett and S. Fletcher, Linear-Scan Anodic Stripping Voltammetry with Thin-Film Electrodes: Theory of the Stripping Stage and Experimental Tests, Anal. Chem., 1997, 69(14), 2673-2681.

34 R. J. Grim, Catalytic Activity of an Intermetallic Compound of Cadmium and Copper in the Vapor-phase Reduction of Nitrobenzene, J. Phys. Chem., 1942, 46(4), 464-469. 
35 J. Ping, Y. Wang, J. Wu and Y. Ying, Development of an electrochemically reduced graphene oxide modified disposable bismuth film electrode and its application for stripping analysis of heavy metals in milk, Food Chem., 2014, 151, 65-71.
36 Y.-F. Sun, L.-J. Zhao, T.-J. Jiang, S.-S. Li, M. Yang and X.-J. Huang, Sensitive and selective electrochemical detection of heavy metal ions using amino-functionalized carbon microspheres, J. Electroanal. Chem., 2016, 760, 143150. 